\title{
Glucagon-like peptide 2 decreases mortality and reduces the severity of indomethacin-induced murine enteritis
}

\author{
ROBIN P. BOUSHEY, BERNARDO YUSTA, AND DANIEL J. DRUCKER \\ Department of Medicine, Banting and Best Diabetes Centre, The Toronto \\ General Hospital, University of Toronto, Toronto, Canada M5G2C4
}

\begin{abstract}
Boushey, Robin P., Bernardo Yusta, and Daniel J . Drucker. Glucagon-like peptide 2 decreases mortality and reduces the severity of indomethacin-induced murine enteritis. Am. J . Physiol. 277 (Endocrinol. Metab. 40): E937-E 947, 1999.-Glucagon-like peptides (GLPs) are secreted from enteroendocrine cells in the gastrointestinal tract. GLP-1 actions regulate blood glucose, whereas GLP-2 exerts trophic effects on intestinal mucosal epithelium. Although GLP-1 actions are preserved in diseases such as diabetes, GLP-2 action has not been extensively studied in the setting of intestinal disease. We have now evaluated the biological effects of a human GLP-2 analog in the setting of experimental murine nonsteroidal antiinflammatory drug-induced enteritis. Human (h)[Gly²]GLP-2 significantly improved survival whether administered before, concomitant with, or after indomethacin. h[Gly²]GLP-2-treated mice exhibited reduced histological evidence of disease activity, fewer intestinal ulcerations, and decreased myeloperoxidase activity in the small bowel ( $\mathrm{P}<0.05$, h[Gly²]GLP-2- vs. saline-treated controls). h[Gly²]GLP-2 significantly reduced cytokine induction, bacteremia, and the percentage of positive splenic and hepatic bacterial cultures ( $P<0.05)$. h[Gly $\left.{ }^{2}\right]$ GL P-2 enhanced epithelial proliferation ( $P<0.05$ for increased crypt cell proliferation in h[Gly $\left.{ }^{2}\right]$ GLP-2- vs. saline-treated mice after indomethacin) and reduced apoptosis in the crypt compartment $(P<0.02)$. These observations demonstrate that a human GLP-2 analog exerts multiple complementary actions that serve to preserve the integrity of the mucosal epithelium in experimental gastrointestinal injury in vivo.
\end{abstract}

glucagon-like peptide 1; peptide hormone; glucagon

THE DIFFUSE ENTEROENDOCRINE SYSTEM contains highly specialized cell types that secrete gastrointestinal hormones with pleiotropic effects on gastrointestinal motility, pancreatic function, and metabolic homeostasis. Whereas several enteroendocrine cells secrete predominantly a single peptide hormone, enteroendocrine cells that express the proglucagon gene give rise to several proglucagon-derived cleavage products, including glicentin, oxyntomodulin, glucagon-like peptide 1 (GLP$1)$, GLP-2, and two smaller intervening peptides, IP-1 and IP-2 $(6,22)$.

Whereas the physiological relevance of glicentin and oxyntomodulin remains unclear, the actions of GLP-1 have been extensively studied. Although the 37-amino acid GLP-1 molecule does not exhibit significant biological activity, processing at the $\mathrm{NH}_{2}$ terminus gives rise to GLP-1-(7-37) and GLP-1-(7-36)amide, peptides

The costs of publication of this article were defrayed in part by the payment of page charges. The article must therefore be hereby marked "advertisement" in accordance with 18 U.S.C. Section 1734 solely to indicate this fact. that stimulate glucose-dependent insulin secretion, inhibit glucagon secretion and gastric motility, and modulate food intake (6). GLP-1 also exhibits actions in the central nervous system, including regulation of food and water intake, thermoregulation, and pituitary hormone secretion (6). Furthermore, GLP-1 may also regulate blood pressure and tracheal mucuous secretion. The essential role of GLP-1 in physiology is exemplified by studies using GLP-1 antagonists or GLP-1R-/- mice. These experiments have shown that GLP-1 plays an essential role in the regulation of glucose homeostasis in both rodents and human subjects $(12,18,31,38)$.

In contrast to the well-defined actions of GLP-1, the biology of GLP-2 is less well understood. We recently demonstrated that GLP-2 exhibits trophic properties in both the small and large bowel rodent epithelium $(8,9)$. GLP-2 administered to normal rodents enhanced crypt cell proliferation and reduced apoptosis (34), and treatment of mice with GLP-2 significantly enhanced barrier function and decreased permeability of the small bowel epithelium (1). Furthermore, GLP-2 prevented parenteral nutrition-associated intestinal mucosal atrophy (4) and partially augmented intestinal adaptation, as assessed by increased mucosal weight gain, sucrase activity, and xylose absorption in rats after major small bowel resection (30).

The factors important for barrier function and maintenance of epithelial mucosal integrity in the small bowel epithelium are complex and include local and systemically derived growth factors such as GLP-2, prostaglandins, endogenous gut bacterial flora, mucins, and trefoil factors. Intestinal injury and inflammation are commonly associated with increased expression of gut growth factors, and considerable experimental evidence suggests that growth factors such as epidermal growth factor, transforming growth factor $-\alpha$ (TGF- $\alpha$ ), TGF- $\beta$, and keratinocyte growth factor (KGF) contribute to epithelial restitution and healing both in vitro and in vivo $(26,27)$. Experiments using genetically engineered mice for overexpression or elimination of TGF $-\alpha$ activity provide important evidence correlating the level of TGF- $\alpha$ expression with the susceptibility to epithelial injury in the colon $(13,14)$. Similarly, goblet cell-derived intestinal trefoil factor (ITF) promotes mucosal epithelial healing, and ITF-/- mice exhibit enhanced susceptibility to colonic epithelial injury that is corrected after ITF administration (21). These observations raise the possibility that molecules, which normally maintain barrier function and/or stimulate epithelial repair in the gastrointestinal tract, may be therapeutically useful for attenuating mucosal injury 
or enhancing epithelial repair after intestinal damage in vivo.

Although GLP-1 and related molecules, such as exendin-4, have been shown to exert their effects in animal models of disease, principally experimental diabetes, it is not known whether GLP-2 actions in the small bowel are preserved in the presence of intestinal inflammation. GLP-2 administered to mice with dextran sulfate-induced colitis resulted in significantly less weight loss and reduction in the extent of mucosal epithelial damage in the large bowel (11). These observations prompted us to examine whether GLP-2 might exert comparable effects in the prevention and/or healing of small bowel epithelial injury in vivo. We now report that GLP-2 significantly reduces mortality and decreases intestinal injury in mice after nonsteroidal antiinflammatory drug (NSAID) administration in vivo.

\section{METHODS}

Animals and experimental protocol. All experiments were carried out after experimental ethical guidelines had been approved by the Animal Care Committee of the Toronto Hospital. Groups of 7- to 9-wk-old female CD1 mice (Charles River, Canada), weighing 20-29 g, were housed in plasticbottom wire-lid cages and maintained in a 12:12-h light-dark cycle temperature-controlled room. Four days before the beginning of each experiment, groups of age and sexmatched mice were weighed using a Mettler PJ 300 scale and randomly allocated to treatment groups, with 4-5 mice per cage. In all experiments, animals were injected subcutaneously with either $0.5 \mathrm{ml}$ saline (PBS) alone or $2.5 \mu \mathrm{g}$ h[Gly2]GLP-2, a human GLP-2 anal og (10) dissolved in $0.5 \mathrm{ml}$ PBS, twice daily at 8 AM and 6 PM. Synthetic h[Gly²]GLP-2 (custom synthesis, American Peptide, Sunnyvale, CA) was utilized in the $7 \mathrm{mg} / \mathrm{kg}$ indomethacin studies. Subsequent experiments using a higher dose of indomethacin $(20 \mathrm{mg} / \mathrm{kg})$ employed recombinant $h\left[G l y^{2}\right] G L P-2$, which is equipotent to synthetic h[Gly²]GLP-2 (a gift of Allelix Biopharmaceuticals, Mississauga, ON, Canada). Indomethacin (1-[p-chlorobenzoyl]-5-methoxy-2-methylindole-3-acetic acid, Sigma Chemical, St. Louis, MO, lot 74H1212) was dissolved in $1 \mathrm{ml}$ anhydrous ethyl alcohol and further diluted in $\mathrm{NaHCO}_{3} \mathrm{pH}$ 7.3. Mice were fasted for $12 \mathrm{~h}$ and then refed for $1 \mathrm{~h}$ before receiving the first subcutaneous injection of freshly prepared indomethacin (or vehicle alone). For the remainder of the experimental period, animals were allowed unlimited access to rodent chow and water.

With the exception of the survival experiments depicted in Fig. 1A, the remainder of the experimental analyses were carried out in mice pretreated with saline or $\mathrm{h}\left[\mathrm{Gly} \mathrm{y}^{2}\right] \mathrm{GLP}-2$ for 4 days before and an additional 2 days concomitant with indomethacin administration. Mice were euthanized 12 and $24 \mathrm{~h}$ after receiving the second dose of indomethacin.

Myeloperoxidase assay. Segments of jejunum, ileum, and colon were obtained for myel operoxidase (M PO) analysis $8 \mathrm{~cm}$ distal to the gastroduodenal junction, $10 \mathrm{~cm}$ from theileocecal junction, and $4 \mathrm{~cm}$ from the anus, respectively. MPO activity of a 3-cm segment of jejunum and ileum and of a $2-\mathrm{cm}$ segment of colon was assayed spectrophotometrically, as previously described $(3,11)$.

RNA extraction and Northern bl ot analysis. Total RNA was extracted from 4-cm segments of jejunum, ileum and colon, and stomach by use of the acid phenol precipitation method (5), and N orthern blotting was carried out using $20 \mu \mathrm{g}$ of total RNA as previously described (7). Nylon membranes were hybridized with cDNA probes labeled with [32P]dATP, hybridized and washed at high stringency, and exposed to X-ray film (Kodak Diagnostic Film, X-OMAT AR) or a phosphorimager screen. Densitometry was performed using the I mage Quant 4.1 program (Molecular Dynamics, Sunnyvale, CA).

Microbiology. Whole blood was obtained via sternotomy and cardiac puncture before the abdominal cavity was entered, after which the spleen and liver were removed and homogenized in sterile PBS. Aliquots of whole blood and tissue homogenates were immediately plated on blood agar plates (aerobic analyses) or on fastidious anaerobic agar (FAA) plates (anaerobic analyses) at $37^{\circ} \mathrm{C}$. Bacterial patho-

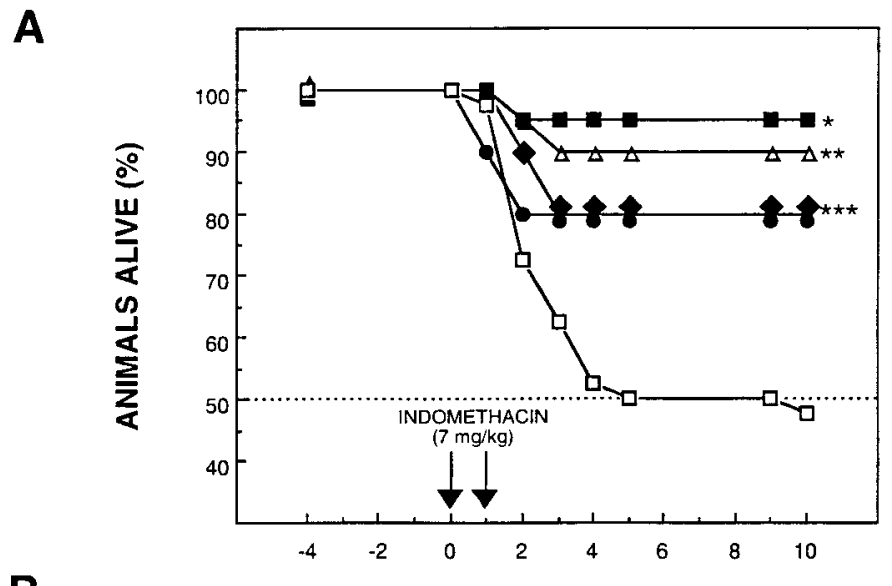

B
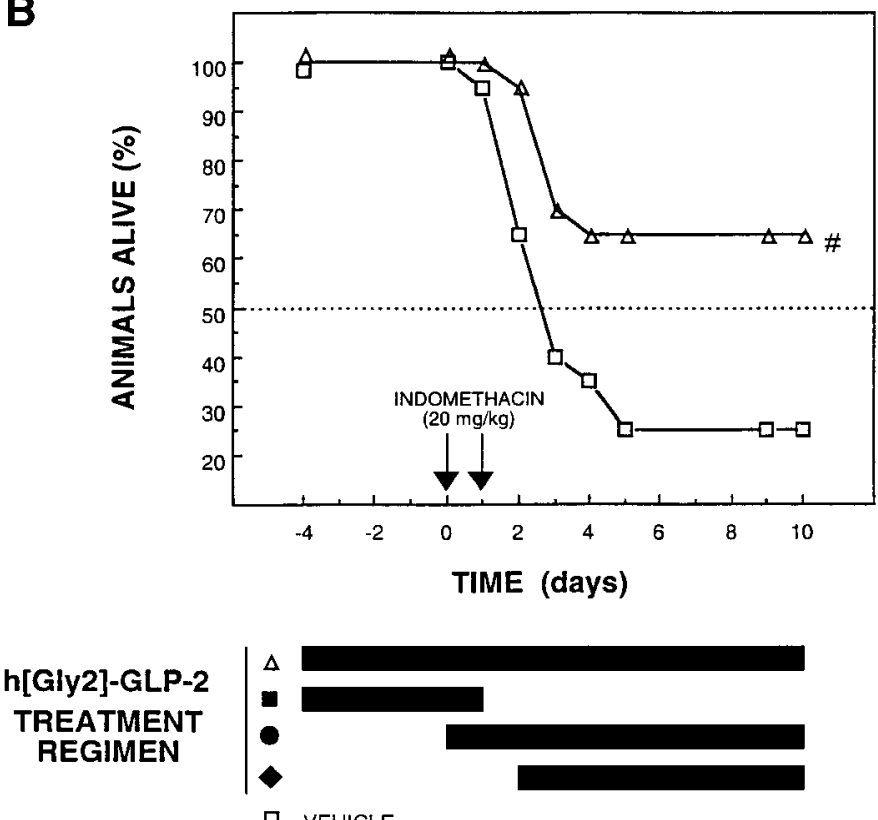

Fig. 1. Animal survival in groups of $C D 1$ mice in protocols $A$ and $B(n=20$ mice for each treatment group, except for vehicle-treated mice administered $7 \mathrm{mg} / \mathrm{kg}$ in $\mathrm{A}$, where $\mathrm{n}=40$ ) was assessed after administration of 2 doses of indomethacin $(7 \mathrm{mg} / \mathrm{kg}$, A, and $20 \mathrm{mg} / \mathrm{kg}$, B). For protocol shown in A, indomethacin $(7 \mathrm{mg} / \mathrm{kg})$ was administered as illustrated, and mice were treated with varying regimens (pretreatment, cotreatment, and posttreatment) of either saline or an anal og of human glucagon-like peptide 2 (h[Gly $\left.{ }^{2}\right] \mathrm{GL}$ P-2). For protocol depicted in $\mathrm{B}$, mice were pretreated for 4 days with either vehicle (saline) or h[Gly ${ }^{2}$ GLP-2, and a higher dose of indomethacin (20 $\mathrm{mg} / \mathrm{kg}$ ) was admi nistered in 2 doses, $24 \mathrm{~h}$ apart. Mice were administered saline (vehicle) or h[Gly ${ }^{2}$ GLP-2 $(2.5 \mu \mathrm{g})$ twice daily in various treatment regimens as indicated. $* \mathrm{P}<0.002$, $* * \mathrm{P}<0.006$, $* * * \mathrm{P}<$ 0.05, \#P $<0.03$, saline- vs. h[Gly²]GLP-2-treated mice. 
gens were identified in the Toronto Hospital microbiology laboratory with standard techniques. Blood agar and FAA plates were obtained from the Toronto Hospital Microbiology Lab (lot 080404M-20). Gram-negative organisms were subcultured onto MacConkey agar without Crystal Violet (lot 072686M ). $\beta$-Glucuronidase (lot no. 25922) and spot indole tests were used to confirm the presence of Escherichia coli. Suspected streptococcal species were subcultured on blood agar plates (lot 080404M-20). A bile aescul in test (lot 2867988) and L-pyrolidonyl- $\beta$-naphthylamide-impregnated discs were used to confirm the presence of enterococcus. E. coli and Streptococcus faecalis served as positive controls in each experiment.

ELISA cytokine analysis. For cytokine analysis, the entire small bowel was snap-frozen in liquid nitrogen and stored at $-70^{\circ} \mathrm{C}$. Tissue was homogenized in $\mathrm{H}_{2} \mathrm{O}$ containing $10 \%$ Trasylol-EDTA-Diprotin A (5000 kallikrein-inhibitor units/ $\mathrm{ml}: 32 \mathrm{mM}: 0.1 \mathrm{nM}$ ) and $0.1 \mathrm{mg} / \mathrm{ml}$ phenylmethylsulfonyl fluoride (PMSF) and then sonicated, and the cellular debris was centrifuged, after which the supernatant was then aliquoted and snap-frozen. E LISA cytokine kits for interleukin-2 (I L-2, Iot no. I 122201), IL-10 (lot no. J 032503), tumor necrosis factor- $\alpha$ (TNF- $\alpha$, lot no. J 072307), and interferon- $\gamma$ (IF N- $\gamma$, lot no. J 060401) were obtained from Biosource I nternational (Camarillo, CA).

Histological analysis. Intestinal weights and morphology were assessed as described previously $(9,11)$. Intestinal segments for histology were taken from the duodenum (adjacent to the pylorus), proximal jejunum ( $2 \mathrm{~cm}$ distal to the pylorus), midjejunum (12 cm distal to the pylorus), distal ileum (immediately proximal to the ileocecal junction), and the colon (immediately distal to the ileocecal junction). Tissues were fixed in $10 \%$ buffered Formalin and embedded in paraffin using standard techniques. Four- to six-micrometer cross sections from each mouse were cut and stained with hematoxylin and eosin. I ntestinal micrometry was performed using a Leica Q500MC Image Analysis System. Twenty well-oriented villi and crypts from each small intestinal section were used to determine villus height and crypt depth. Disease severity was graded in a blinded manner by two observers on a scale from 0 to 4 according to a standard scoring system (20): 0, normal bowel; 1 , epithelial loss confined to the villus tip; 2, epithelial detachment from the underlying Iamina propria; 3, epithelial detachment involv-

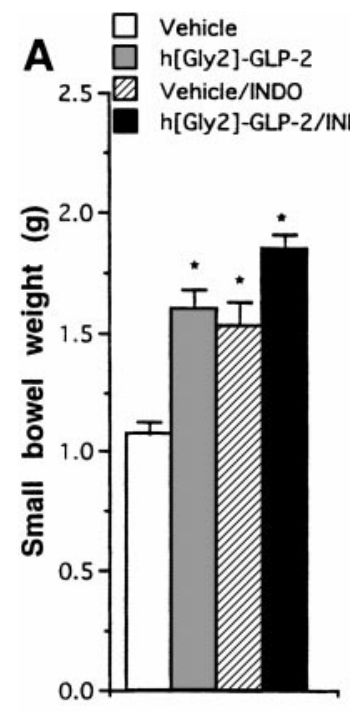

C

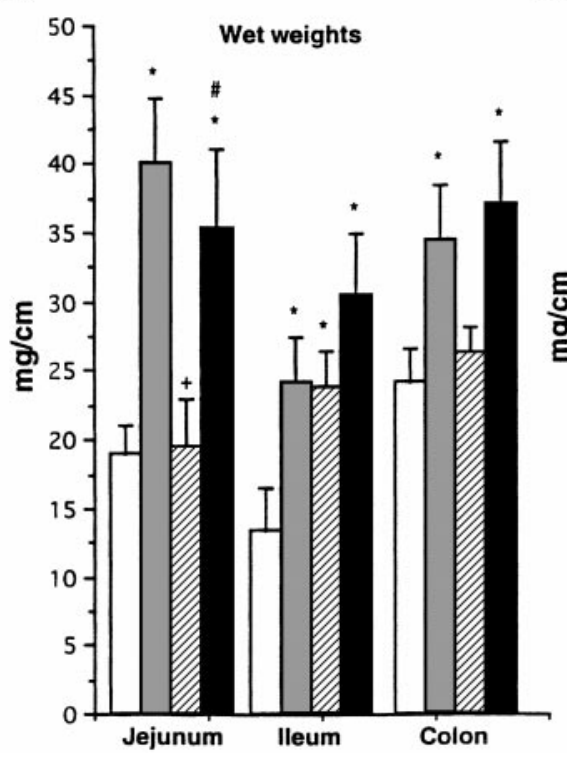

D
B
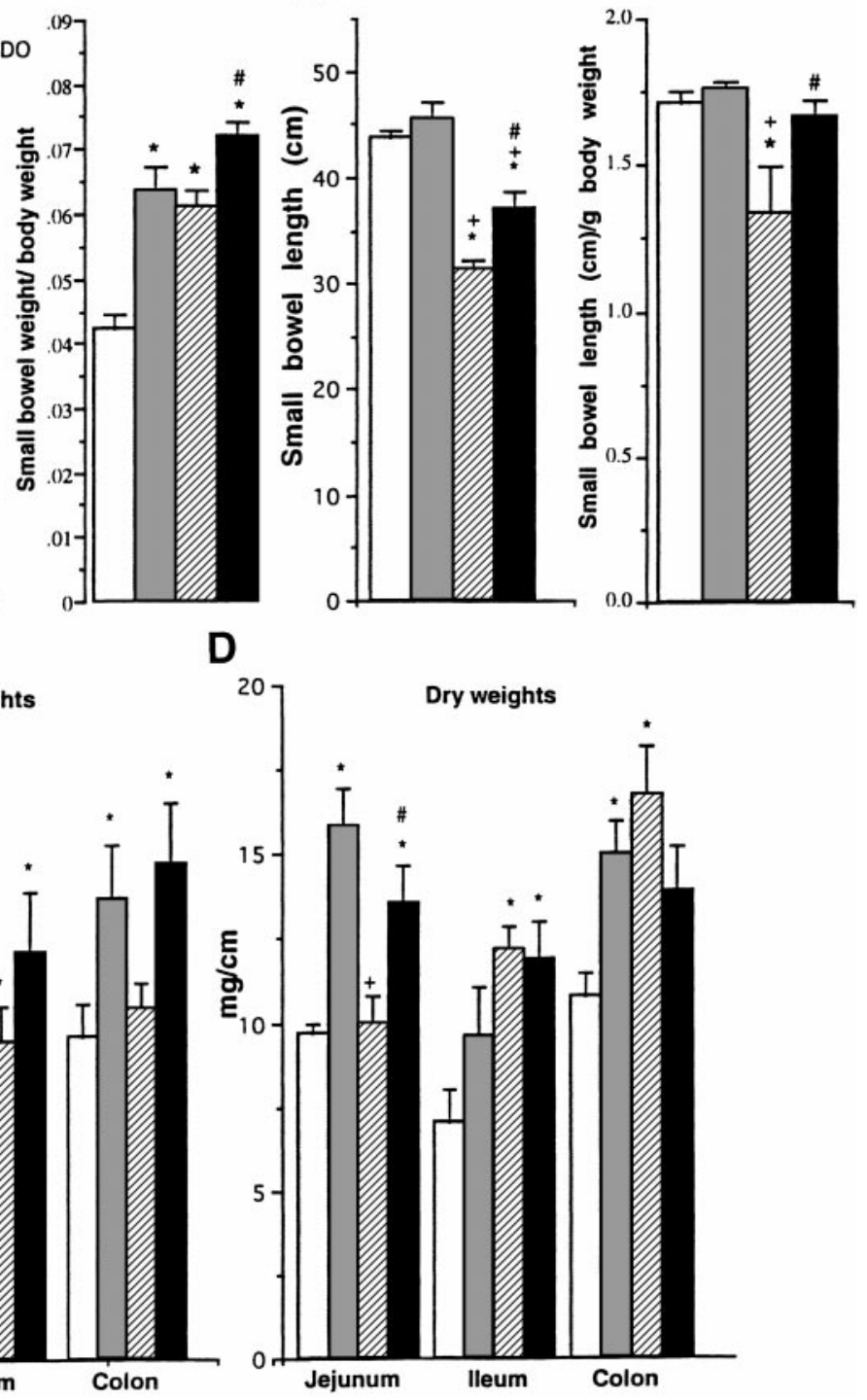

Fig. 2. Total small bowel weight (A), length (B), and wet (C) and dry (D) weights from jejunum, ileum, and colon of control and indomethacin (INDO)-treated mice given either saline or $h\left[\mathrm{Gly}^{2}\right] \mathrm{GLP}-2$. Mice were treated with saline or h[Gly2]GLP-2 for a total of 6 days and were euthanized $24 \mathrm{~h}$ after the 2nd dose of indomethacin. $* \mathrm{P}<$ 0.05 , saline-treated control mice vs. either h[Gly $\left.{ }^{2}\right]$ GLP-2-treated controls or mice exposed to $20 \mathrm{mg} / \mathrm{kg}$ indomethacin and treated with either saline or h[Gly²]GLP-2. For small bowel and colon weights, $+\mathrm{P}<$ 0.005 for h[Gly²]GLP-2-treated control mice vs. indomethacin-treated mice receiving either saline or h[Gly ${ }^{2}$ GLP-2. \#P $<0.05$ for indomethacin-treated mice receiving either saline or $\mathrm{h}\left[\mathrm{Gly}^{2}\right] \mathrm{GLP}-2$. For small bowel length, $* P<0.02$, saline-treated control mice vs. either h[Gly $\left.{ }^{2}\right]$ GLP-2treated controls, or mice exposed to 20 $\mathrm{mg} / \mathrm{kg}$ indomethacin and treated with either saline or $\mathrm{h}\left[\mathrm{Gly}^{2}\right] \mathrm{GLP}-2 ;+\mathrm{P}<0.005$ for h[Gly $\left.{ }^{2}\right]$ GLP-2-treated control mice vs. indomethacin-treated mice receiving either saline or h[Gly $\left.{ }^{2}\right] \mathrm{GLP}-2$; \#P $<0.01$ for indomethacin-treated mice receiving either saline or h[Gly²]GLP-2. 
ing less than one-half of the villus; 4, epithelial detachment involving more than one-half of the villus and/or ulceration. Crypt cell proliferation index was assessed by proliferating cell nuclear antigen staining, and the epithelial apoptosis index was assessed by determining the percentage of Tdtmediated dUTP nick end labeling (TUNEL)-positive apoptotic cells per crypt (number of positive cells/100 crypts), as previously described $(9,28,34)$.

Statistical analysis. Survival analysis was performed using the Fisher's exact t-test. Statistical differences between treatment groups were determined by ANOVA and Student's t-test. Differences were considered significant at the $P<0.05$ level.

\section{RESULTS}

Because the degree of NSAID-induced enteritis appears to be dose dependent in rats and mice, we initially analyzed the effects of several different concentrations of indomethacin on the induction of intestinal inflammation and subsequent mortality. Mice administered $7 \mathrm{mg} / \mathrm{kg}$ indomethacin once daily for 2 days (Fig. 1A) exhibited a $52.5 \%$ mortality, whereas the higher dose of $20 \mathrm{mg} / \mathrm{kg}$ resulted in a mortality rate of $75 \%$ (Fig. 1B ). To determinethe consequences of administering h[Gly $\left.{ }^{2}\right]$ GLP-2 to indomethacin-treated $(7 \mathrm{mg} / \mathrm{kg}$ ) mice, we initially analyzed mortality in mice treated with h[Gly $\left.{ }^{2}\right]$ GLP-2 administered concomitantly with the first dose of indomethacin or $24 \mathrm{~h}$ after the second dose of indomethacin (Fig. 1A). h[Gly²]GLP-2 administration concomitant with, or after, indomethacin significantly increased the survival rate of indomethacintreated mice (Fig. 1A, P $<0.05$, h[Gly²]GLP-2- vs. saline-treated mice).

To examine the consequences of different GLP-2 treatment regimens on protection against NSAIDinduced epithelial damage, either mice were pretreated with h[Gly ${ }^{2}$ GLP-2 for 4 days before and for an additional 2 days coincident with the administration of indomethacin, or the h[Gly²]GLP-2 was administered 4 days before, concomitant with, and for an additional 9 days after the last dose of indomethacin. Remarkably, both the pretreatment regimens significantly protected against NSAID-induced mortality (Fig. 1A, 90-95\% survival, $\mathrm{P}<0.002$, h[Gly²]GLP-2- vs. saline-treated controls).

The protective effects of h[Gly $\left.{ }^{2}\right] \mathrm{GLP}-2$ were not restricted to the $7 \mathrm{mg} / \mathrm{kg}$ dose of indomethacin, as h[Gly ${ }^{2}$ ]GLP-2 also significantly increased the survival rate of mice treated with a larger dose of indomethacin, $20 \mathrm{mg} / \mathrm{kg}$ (Fig. 1B, P < 0.03, h[Gly²]GLP-2- vs. salinetreated controls). In all treatment regimens, $\mathrm{h}\left[\mathrm{Gly}^{2}\right]$ GLP-2-treated mice appeared healthier and more active (after indomethacin) than saline-treated mice, who often appeared lethargic, particularly after the 20 $\mathrm{mg} / \mathrm{kg}$ dose.

To delineate the mechanisms underlying the h[Gly²]GLP-2-associated improvement in survival, we studied separate groups of mice pretreated with saline or h[Gly2]GLP-2 for 4 days, then treated with both h[Gly2]GLP-2 and indomethacin for an additional 2 days, and finally euthanized mice for detailed analyses 12-24 $\mathrm{h}$ after the second dose of indomethacin (20 $\mathrm{mg} / \mathrm{kg}$ ). Six days of h[Gly²]GLP-2 treatment in normal control mice induced a significant increase in small bowel weight (Fig. 2A, saline- vs. h[Gly $\left.{ }^{2}\right]$ GLP-2-treated mice, $\mathrm{P}<0.05$ ) evident in both jejunum and ileum (Fig. 2C); colon weight was also significantly increased by h[Gly ${ }^{2}$ ]GLP-2 (Fig. 2C, P $<0.05$ for h[Gly2]GLP-2- vs. saline-treated mice). Indomethacin-treated micereceiving h[Gly $\left.{ }^{2}\right]$ GL P-2 had significantly increased wet and dry jejunal weights $(P<0.05$ for wet and dry jejunal weights from saline-vs. h[Gly $\left.{ }^{2}\right] G L P$-2-treated mice, Fig. 2, C and D). Furthermore, indomethacin treatment produced a significant shortening in small bowel length (Fig. 2B, P < 0.05) that was partially reversed in mice treated with both indomethacin and $\mathrm{h}\left[\mathrm{Gly}^{2}\right] \mathrm{GLP}-2$ (Fig. $2 \mathrm{~B}, \mathrm{P}<0.05$ for $\mathrm{h}\left[\mathrm{Gly} \mathrm{y}^{2}\right] \mathrm{GLP}-2$ vs. salinetreated mice exposed to indomethacin). Taken together, these observations demonstrate that $h\left[\right.$ Gly $\left.y^{2}\right]$ GL P-2 produces significant changes in the small bowel despite the concomitant presence of NSAID-induced inflammation.

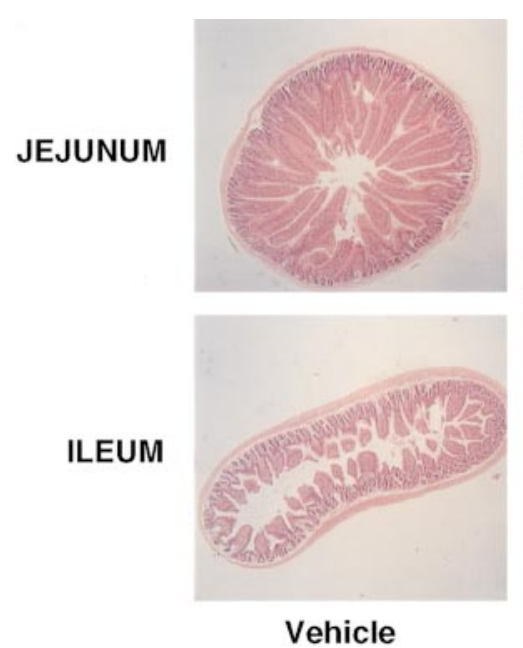

Vehicle
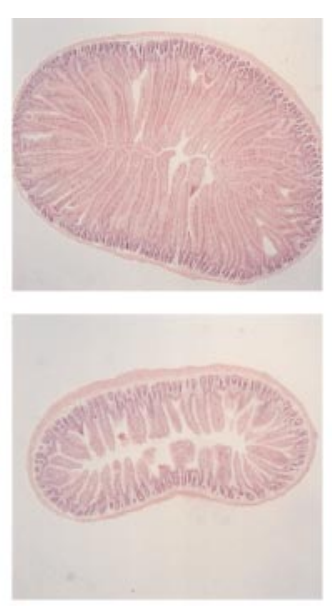

h[Gly2]-GLP-2
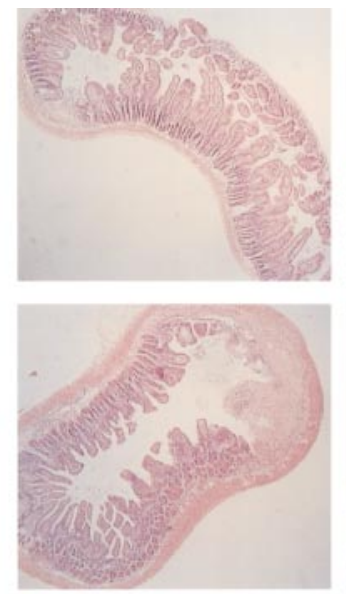

Vehicle/INDO
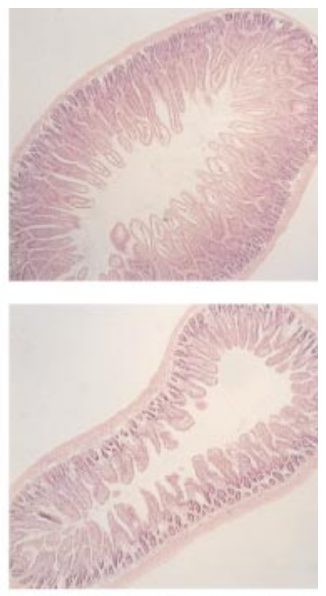

h[Gly2]-GLP-2/INDO

Fig. 3. Photomicrographs of hematoxylin-eosin-stained transverse intestinal sections from jejunum and ileum of saline (vehicle) and h[Gly²]GLP-2-treated mice treated with or without indomethacin (INDO). Magnification $\times 40$. 
Treatment of control mice with h[Gly $\left.{ }^{2}\right]$ GLP-2 for 6 days induced significant increases in villus height (Figs. 3-5 and 6A, P $<0.05$ for saline- vs. h[Gly²]GLP-2treated mice for duodenum, jejunum, and ileum) and crypt depth (Fig. 6B, P $<0.05$, saline - vs. h[Gly²]GLP-2treated groups). Mice given indomethacin and saline injections exhi bited significant decreases in villus height in both proximal and midjejunal regions (Figs. 3- 5 and $6 \mathrm{~A} ; \mathrm{P}<0.05$, for salinetreated controls vs. saline treated mice given indomethacin, Fig. 6A), consistent with previous findings (15). In contrast, the loss in villus height after indomethacin was significantly re- versed in the proximal and midjejunum (Figs. 3-5 and $6 \mathrm{~A}$ ) of mice pretreated with $\mathrm{h}\left[\mathrm{Gly} \mathrm{y}^{2}\right] \mathrm{GL} \mathrm{P}-2(\mathrm{P}<0.05$ for saline vs. h[Gly $\left.{ }^{2}\right] G L P-2$-treated mice receiving indomethacin). Similarly, crypt depth was significantly greater in the midjejunum of indomethacin-treated mice receiving $\mathrm{h}\left[\mathrm{Gly}^{2}\right] \mathrm{GLP}-2$ (Fig. 6B, $\mathrm{P}<0.05$ for saline vs. h[Gly $\left.{ }^{2}\right] G L P-2$-treated mice after indomethacin). These findings demonstrate that many of the histological consequences of indomethacin administration are ameliorated by treatment with h[Gly²]GLP-2.

To determine the mechanisms underlying $h\left[\mathrm{Gly}^{2}\right]$ GLP-2 action in the setting of NSAID-induced enteritis,

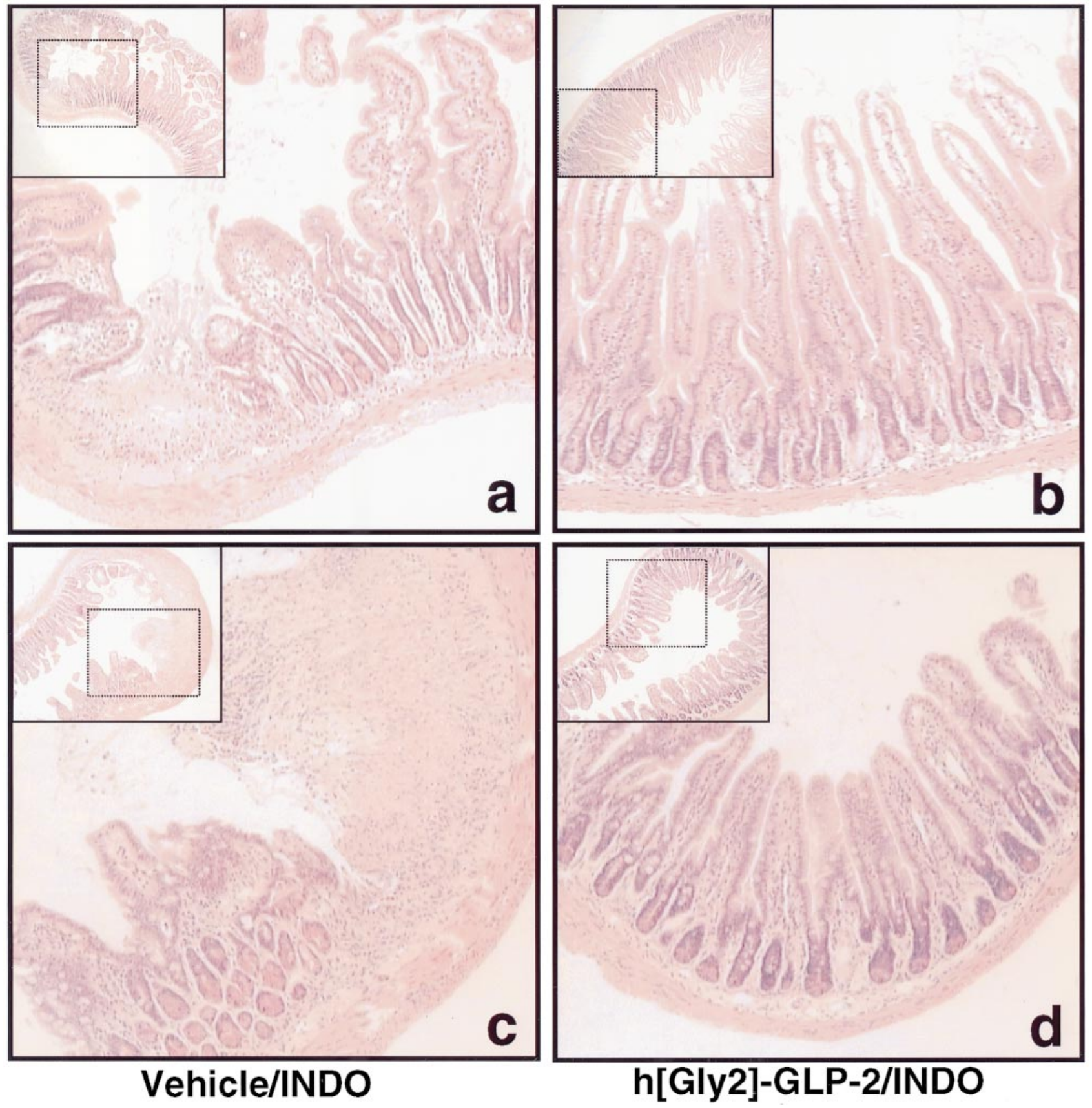

Fig. 4. Higher power magnification of histological sections from jejunum (A and B) and ileum (C and D) of indomethacin-treated mice coadministered either with saline (Vehicle/l NDO) or h[Gly $\left.{ }^{2}\right] \mathrm{GLP}-2$ (h[Gly²]GLP-2/ INDO). 

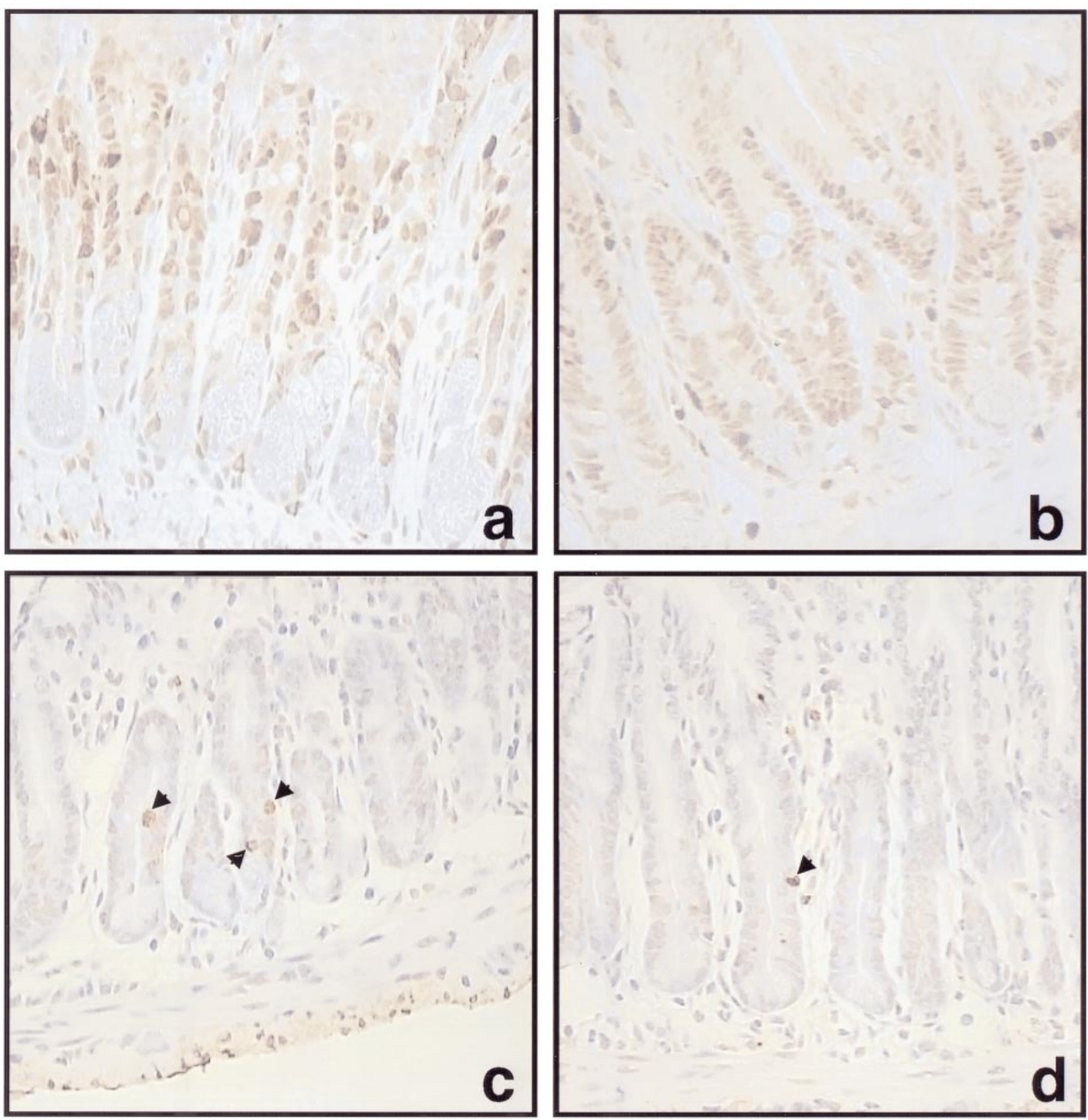

Vehicle/INDO

\section{h[Gly2]-GLP-2/INDO}

Fig. 5. Proliferating cell nuclear antigen (PCNA)-positive (A and B) and TdT-mediated dUTP nick end labeling (TUNEL)-positive (C and D) cells (arrowheads) in crypt compartment from jejunum of indomethacin-treated mice. Magnification $\times 200$ for $B$ and $C$.

we examined the rates of both crypt cell proliferation and apoptosis in indomethacin-treated mice. $\mathrm{h}\left[\mathrm{Gly}^{2}\right]$ GLP-2 treatment significantly increased the crypt cell proliferation rate (CCPR) in wild-type mice (Fig. 6D). Indomethacin treatment alone increased the CCPR, and $\mathrm{h}\left[\mathrm{Gly}^{2}\right] \mathrm{GLP}-2$ significantly augmented the CCPR in indomethacin-treated mice (Figs. 5 and 6D). The number of apoptotic crypt cells was markedly increased after indomethacin administration, whereas mice treated with both $\mathrm{h}\left[\mathrm{Gly}^{2}\right] \mathrm{GLP}-2$ and indomethacin (INDO) exhibited a significant reduction in crypt cell apoptosis ( $\mathrm{P}<0.01$, INDO vs. h[Gly²]GLP-2 and INDOtreated mice, Figs. 5 and 6C).
To assess the extent of intestinal epithelial injury after indomethacin administration, multiple histological sections from duodenum, jejunum, and ileum were examined by observers blinded to treatment groups. Significantly fewer small bowel ulcerations were observed in proximal and midjejunal sections from mice receiving $h\left[\mathrm{Gly}^{2}\right] \mathrm{GL} P-2$ (Fig. 7A, $\mathrm{P}<0.05$ for saline- vs. h[Gly²] GLP-2-treated mice receiving I NDO). Similarly, h[Gly ${ }^{2}$ GLP -2 treatment markedly reduced the number of mice with free abdominal fluid (Fig. 7B, P < 0.0003) and lowered disease activity scores in the jejunum (Fig. 7C, P $<0.05$ for saline - vs. h[Gly²]GLP-2-treated mice). Similarly, MPO activity, an indicator of neutrophil 

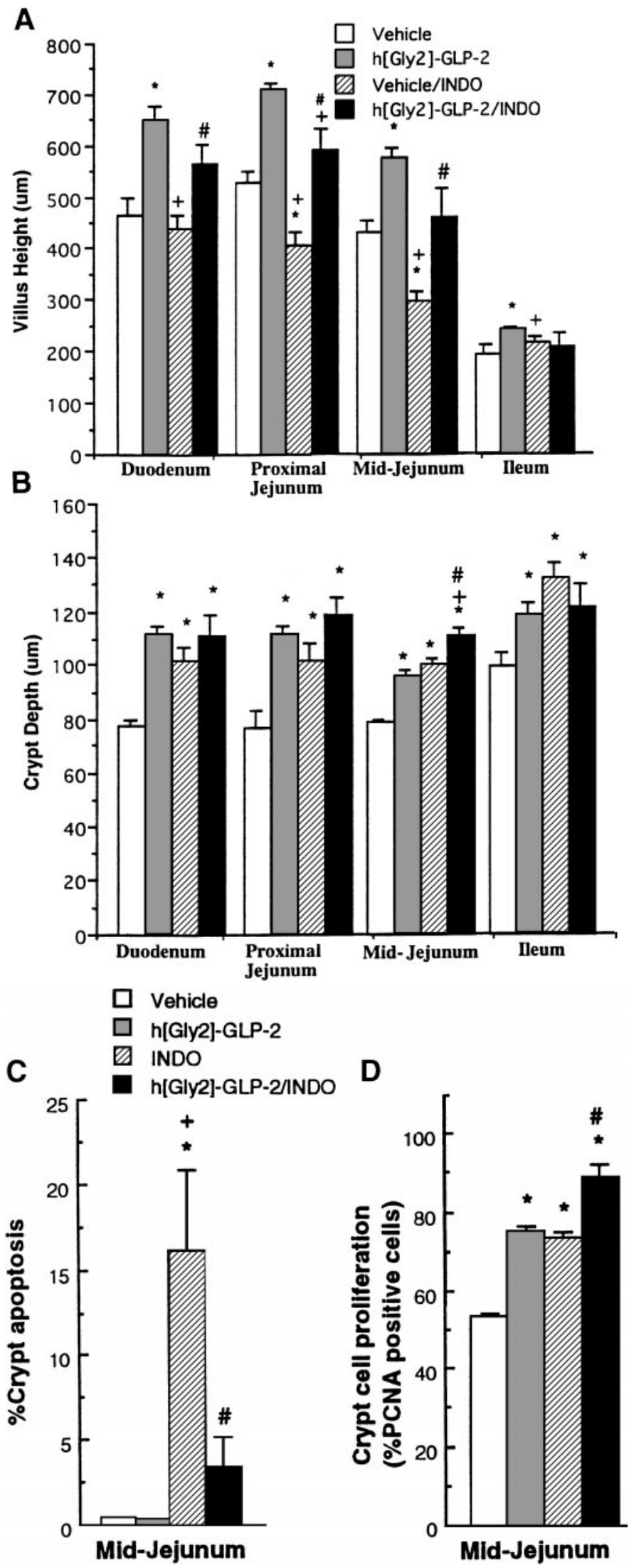
A

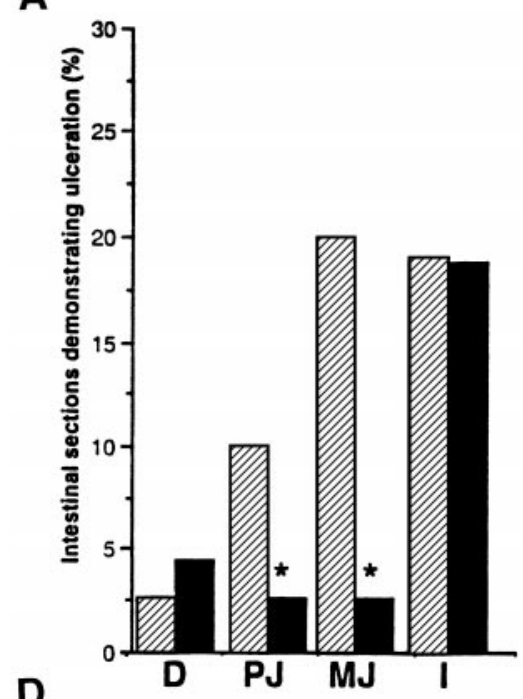

D

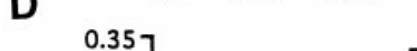

$\left.{ }^{110}{ }^{100}\right]$

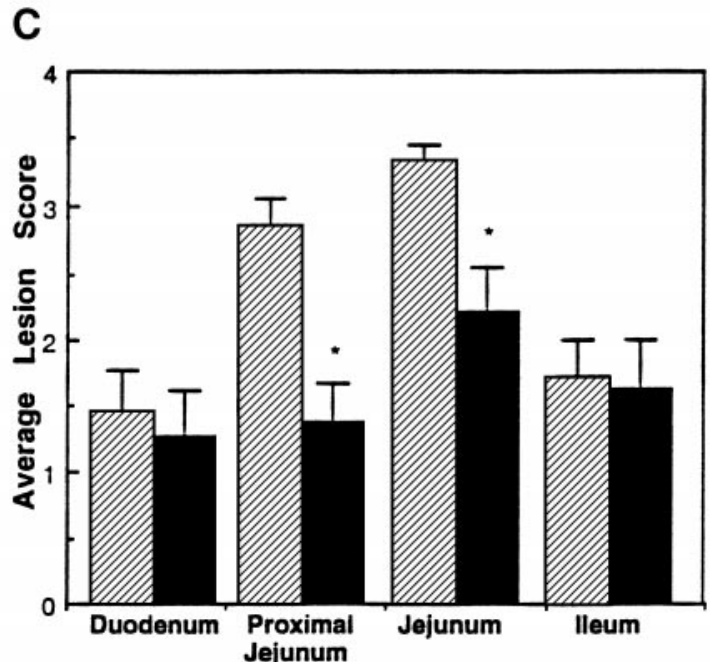

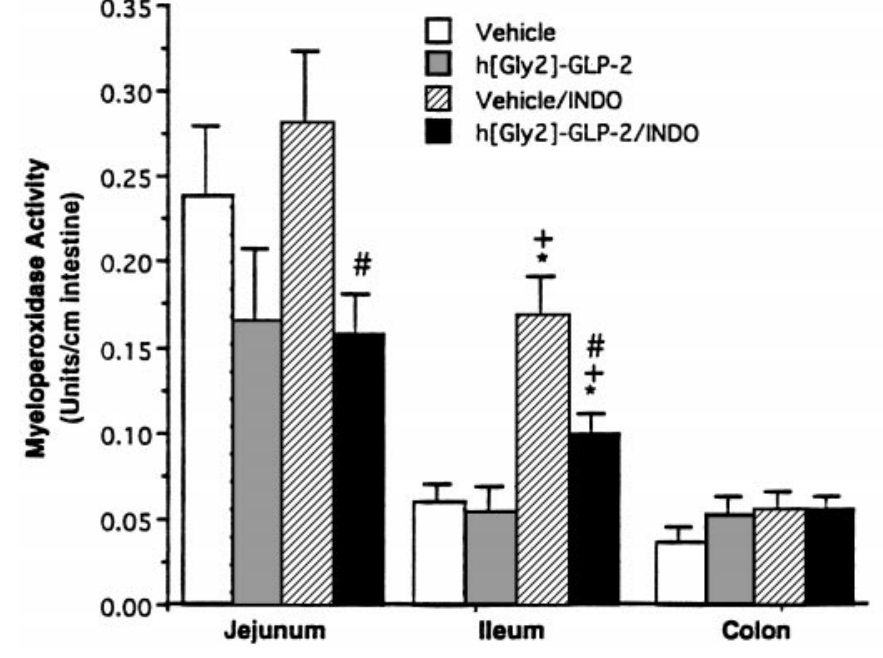

Fig. 7. A: small bowel ulceration, defined as destruction of villus and exposure of lamina propria, in histological sections from duodenum (D), proximal (PJ) and mid- (MJ ) jejunum, and ileum (I) from indomethacin-treated mice. F orty hematoxylin and eosin-stained cross sections from each region, obtained from 6 mice per treatment group, were examined under light microscopy. Total number of ulcers is expressed as a percentage of total number of sections examined. $* P<0.05$, saline vs. $h\left[G_{1}{ }^{2}\right] G L P-2$-treated mice after indomethacin. Experimental groups in A-D are delineated as shown in key (see D). B: percentage of mice with free abdominal fluid at euthanasia $12 \mathrm{~h}$ after the last injection of indomethacin, $20 \mathrm{mg} / \mathrm{kg}$. $* * * * P<0.0001$. C: small bowel lesion scores in duodenum, jejunum, and ileum of indomethacin-treated mice. The average lesion score was calculated by a blinded observer after assessment of 40 histological sections per intestinal region for both saline and h[Gly²]GLP-2-treated mice (4 sections per region from 6 different mice/treatment group). ${ }^{*} \mathrm{P}<0.05$, saline vs. h[Gly ${ }^{2}$ GLP-2-treated mice after indomethacin. D: myeloperoxidase activity in jejunum, ileum, and colon of control and indomethacin-treated mice. $* \mathrm{P}<0.02$, saline-treated control mice vs. either h[Gly $\left.{ }^{2}\right] \mathrm{GLP}-2$-treated controls or mice exposed to $20 \mathrm{mg} / \mathrm{kg}$ indomethacin and treated with either saline or h[Gly2]GLP-2; $+\mathrm{P}<0.05$ for h[Gly²]GLP-2-treated control mice vs. indomethacin-treated mice receiving either saline or $\mathrm{h}\left[\mathrm{Gly}^{2}\right] \mathrm{GLP}-2$; \#P $<0.03$ for indomethacin-treated mice receiving either saline or $h\left[\right.$ Gly $\left.^{2}\right]$ GLP-2.

nisms. Early abnormalities noted after acute indomethacin administration include decreases in microvascular villus blood flow (17), uncoupling of oxidative phosphorylation, and increased intestinal permeability, with mucosal erosions and ulcerations frequently noted within $24 \mathrm{~h}$ of indomethacin administration $(24,39)$. Inhibition of protective prostaglandin synthesis is thought to contribute to development of mucosal injury after NSAID administration; however, mice homozygous for disruption of the prostaglandin synthase 1 gene exhibit a normal gastrointestinal tract and paradoxical resistance to indomethacin-induced ulceration (19). Taken together, these observations clearly illustrate that the pathophysiol ogy of NSAID-induced intestinal injury is complex and likely attributable to multiple disruptions in homeostatic mechanisms that control the integrity of the mucosal epithelium.

Thereduction in mortality observed in h[Gly²] GLP-2treated mice suggests that one or more biological actions of GLP-2 promote resistance to and/or recovery 
A

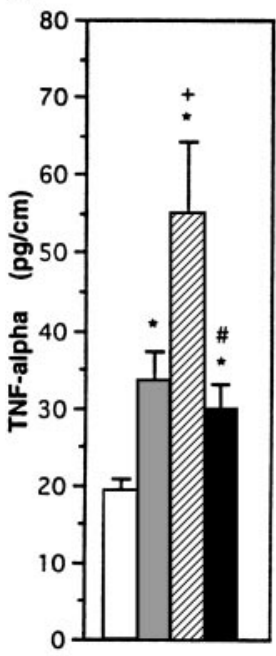

B

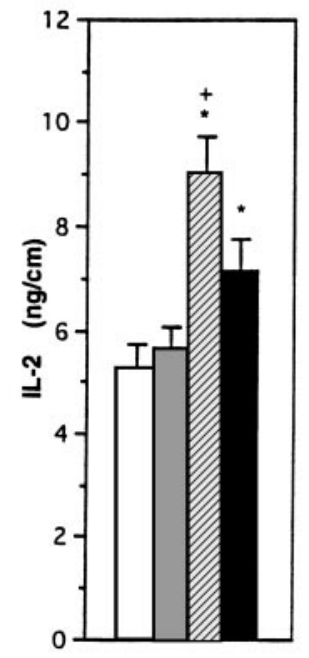

C

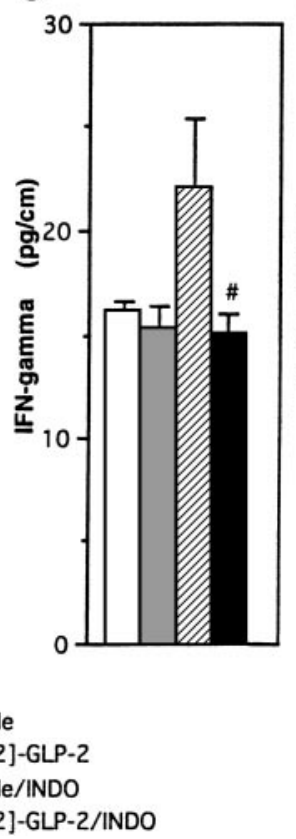

D

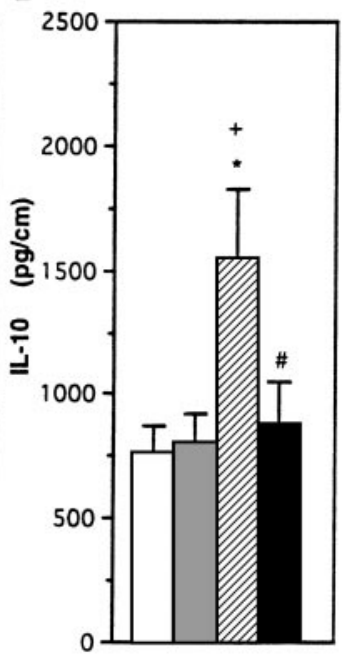

Fig. 8. Tissue cytokine levels in control and indomethacin-treated mice; $\mathrm{n}=10$ mice/treatment group. Values for tumor necrosis factor- $\alpha$ (TNF- $\alpha, A)$, interleukin-2 (IL-2, B), interferon- $\gamma$ (IFN- $\gamma, \mathrm{C})$, and IL-10 (D) are normalized per $\mathrm{cm}$ of small bowel. $* \mathrm{P}<0.05$, vehicle-treated control vs. all other groups of mice; $+\mathrm{P}<$ 0.05 , vehicle-treated mice administered indomethacin vs. vehicle or h[Gly $\left.{ }^{2}\right] \mathrm{GLP}$ 2-treated controls; and \#P $<0.05$, for indomethacin-treated mice receiving saline vs. h[Gly²]GLP-2.

from indomethacin-induced intestinal damage. Furthermore, the finding that $\mathrm{h}\left[\mathrm{Gly} \mathrm{y}^{2} \mathrm{GL} \mathrm{P}-2\right.$ reduces mortality when administered either before or after indomethacin raises the possibility that multiple complementary mechanisms may account for the beneficial actions of GLP-2 in this experimental model. The initial findings, that GLP-2 promotes mucosal epithelial growth via stimulation of crypt cell proliferation and reduction of enterocyte apoptosis in normal mice, have now been extended by the demonstration that h[Gly²]GLP-2 significantly enhances the rate of crypt cell proliferation and markedly reduces crypt cell death in the setting of NSAID-induced inflammation. These findings may provide a mechanism for the reduction in epithelial dam-

A
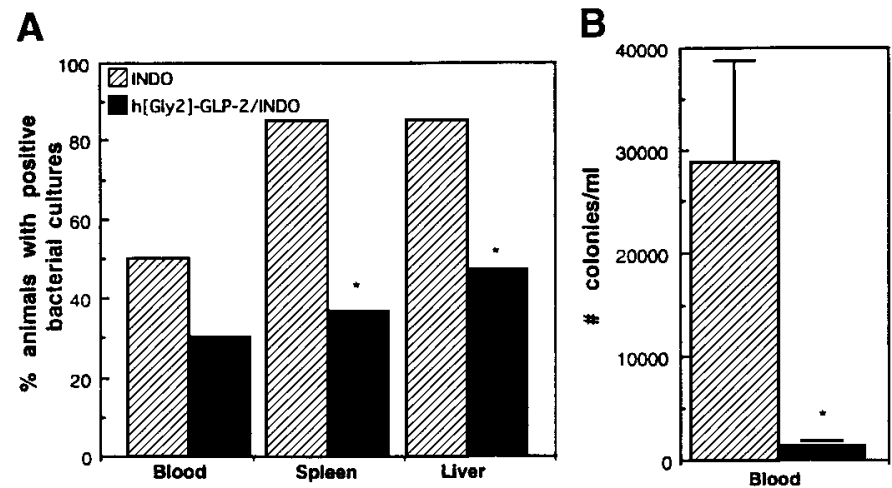

Fig. 9. Prevalence of positive bacterial cultures (aerobic) from blood, splenic, and liver homogenates. Groups of mice $(n=20$ mice for each treatment group) were treated with saline or $h\left[\mathrm{Gly}^{2}\right] \mathrm{GL} P-2$, as shown in Fig. 1B, and all mice were euthanized $12 \mathrm{~h}$ after administration of 2nd dose of indomethacin $(20 \mathrm{mg} / \mathrm{kg}$ ). $* \mathrm{P}<0.03$ for saline- vs. $\mathrm{h}\left[\mathrm{Gly}^{2}\right] \mathrm{GLP}$-2-treated mice after indomethacin. At time of euthanasia, $33 \%$ of saline/INDO vs. $6 \%$ of h[Gly $\left.{ }^{2}\right]$ GLP-2/INDO mice had al ready succumbed and, hence, were not used for further analysis in this experiment.
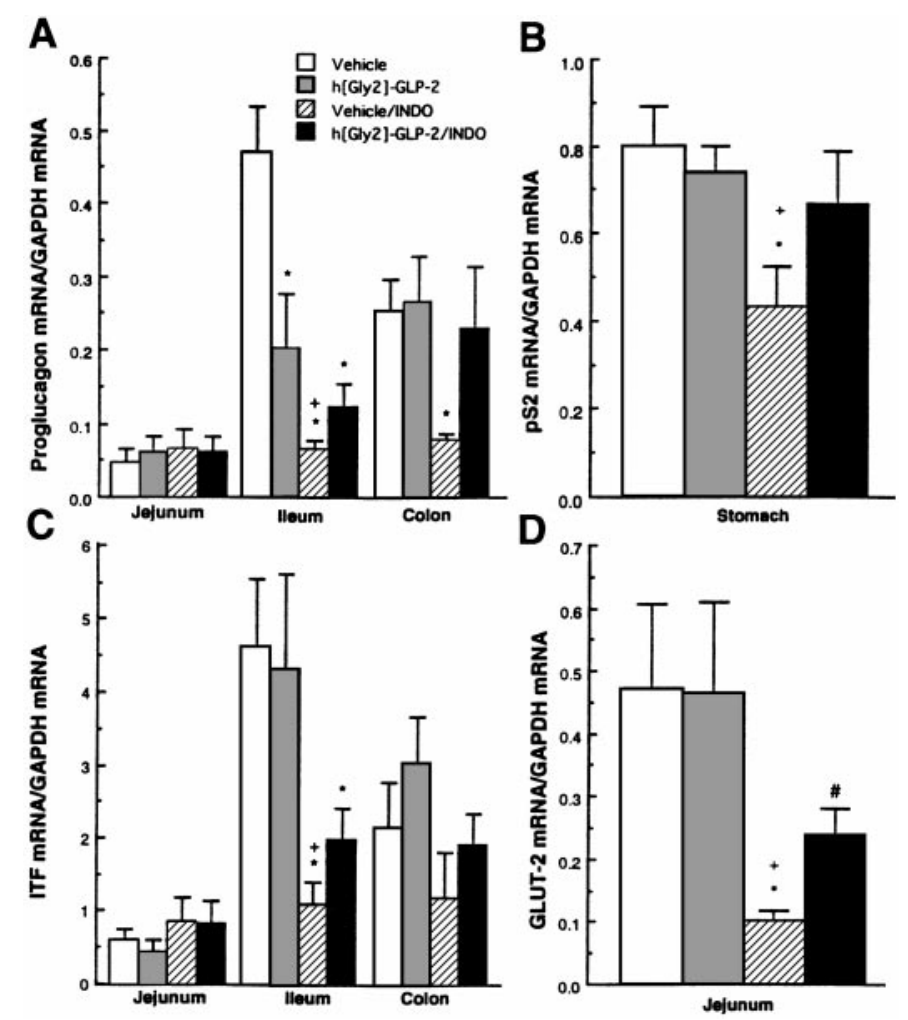

Fig. 10. Relative levels of mRNA transcripts for proglucagon (A), pS2 (B), intestinal trefoil factor (ITF, C), and GLUT-2 (D) in different regions of gastrointestinal tract. Data presented represent mean values from densitometric analysis of $\mathrm{N}$ orthern blot experiments $(\mathrm{n}=$ 5 mice analyzed for each experimental condition). Values are normalized to signals obtained for glyceral dehyde phosphate dehydrogenase (GAPDH) in each sample. *P $<0.05$, vehicle-treated control vs. all other groups of mice; $+\mathrm{P}<0.05$, vehicle-treated mice administered indomethacin vs. vehicle or h[Gly²]GLP-2-treated controls; \#P < 0.05 , indomethacin-treated mice receiving saline vs. h[Gly²]GLP-2. 
age, observed histologically, in h[Gly $\left.{ }^{2}\right]$ GLP-2-treated mice receiving indomethacin.

Themarked reduction in mortality in the h[Gly²]GLP2-treated mice may be explained in part by the reduction in circulating bacteremia in h[Gly²]GLP-2-treated mice. Recent experiments have demonstrated that GLP-2 reduces mucosal permeability in both normal mice and rats subjected to major small bowel resection $(1,4)$. Because luminal bacteria play a significant role in the pathogenesis of indomethacin-induced intestinal injury, the significant reduction in numbers of mice with positive bacterial cultures after h[Gly2]GLP-2 treatment may represent an important mechanism by which h[Gly $\left.{ }^{2}\right]$ GLP-2 increases survival after intestinal injury in vivo.

Neutrophil accumulation and increased MPO activity are common features of indomethacin-induced bowel injury $(24,39)$, and gastric ulceration after indomethacin has been shown to be neutrophil dependent $(36,37)$. Although MPO activity was significantly reduced in the jejunum and ileum of h[Gly $\left.{ }^{2}\right]$ GLP-2-treated mice, the importance of this finding for healing of intestinal mucosa remains unclear. Depletion of circulating neutrophils in rats using anti-neutrophil antisera did not significantly attenuate mortality or prevent the development of intestinal inflammation and increased intestinal permeability (39). Furthermore, histological and biochemical evidence of intestinal inflammation commonly precedes significant neutrophil accumulation in the epithelial mucosa (24). These observations suggest that, although neutrophils represent a prominent component of the inflammatory infiltrate that occurs in the small bowel after indomethacin administration, they may not be essential mediators of indomethacininduced intestinal injury.

Although suppression of prostaglandin synthesis via inhibition of cyclooxygenase 1 in the stomach is thought to play a key rolein the pathogenesis of NSAID-induced gastric damage (35), mice with targeted inactivation of the prostaglandin synthase 1 gene exhibit resistance to indomethacin-induced gastric inflammation (19). Furthermore, additional experimental evidence suggests that NSAID-mediated suppression of prostaglandin synthesis is not thought to play a key role in the induction of small bowel mucosal injury $(29,35)$. In contrast, overproduction of Th1 cytokines has been linked, in both rodent and human studies, to the induction and maintenance of a T cell-mediated intestinal inflammatory response (32), and indomethacin increases TNF $-\alpha$ production in a dose-dependent manner (2). Furthermore, inhibition of TNF- $\alpha$ synthesis reduced intestinal injury after indomethacin in rats (2), and immunoneutralization of TNF- $\alpha$ reduces intestinal inflammation in patients with Crohn's disease (33). The mechanism for the decrease in the levels of intestinal cytokines after h[Gly $\left.{ }^{2}\right]$ GLP-2 treatment in our study has not been determined but may simply reflect the decreased level of intestinal inflammation duetogreater integrity of the mucosal epithelium in h[Gly $\left.{ }^{2}\right]$ GLP-2treated mice.
Analysis of growth factor action in the gastrointestinal tract has revealed that the intestinotrophic and protective effects of some growth factors may be partly indirect, via induction of molecules with direct actions on the epithelial mucosa. F or example, KGF stimulates the release of proglucagon-derived peptides such as GLP-1 and GLP-2 in the rat (25) and also produces goblet cell hyperplasia, raising the possibility that its actions may be mediated by increased trefoil factor release from goblet cells (16). Although levels of ITF and pS2 were reduced in the ileum and stomach, respectively, of indomethacin-treated mice, no significant changes in trefoil factor expression were detected after treatment with $\mathrm{h}\left[\mathrm{Gly} \mathrm{y}^{2}\right] \mathrm{GLP}-2$. Furthermore, in previous studies of mice with dextran sulfate-induced colitis, we found no effect of h[Gly2]GLP-2 on the levels of KGF or TGF- $\alpha$ (11). Hence, the available evidence suggests that the effects of GLP-2 in the gastrointestinal tract are likely direct, via interaction with a recently identified GLP-2 receptor (23).

In summary, h[Gly²]GLP-2 treatment significantly improved survival and histological indexes of disease activity after indomethacin-induced gastrointestinal injury. These actions of GLP-2 are mediated by increased epithelial repair and reduced cell death in the crypt compartment. GLP-2-treated mice also exhibit decreased MPO activity, cytokine expression, and bacterial translocation, providing an explanation for the reduced morbidity and mortality observed in the GLP2-treated animals. Current strategies for treatment of intestinal inflammation are primarily directed toward suppression and elimination of the inflammatory response. The results of the experiments reported here, taken together with the beneficial effects of GLP-2 in experimental colitis (11), suggest that further studies of the biological actions of GLP-2 in the setting of intestinal injury appear warranted.

We thank Feng Wang and Mary Hill for expert technical assistance and Dr. J . Brunton for advice and assistance with microbiology and bacterial cultures.

This work was supported in part by operating grants from the Medical Research Council (MRC) of Canada and Allelix Biopharmaceuticals.

D. Drucker is an MRC Senior Scientist and a consultant to Allelix Biopharmaceuticals. GLP-2 is the subject of a licensing agreement between the Toronto Hospital, the University of Toronto, D. Drucker, and Allelix Biopharmaceuticals.

Address for correspondence and reprint requests: D. J . Drucker, The Toronto Hospital, 200 Elizabeth St. CCRW3-838, Toronto, ON, Canada M5G 2C4 (E-mail: d.drucker@utoronto.ca).

Received 13 May 1999; accepted in final form 29J une 1999.

\section{REFERENCES}

1. Benjamin, M. A., D. M. McKay, P.-C. Yang, and M. H. Perdue. Glucagon-like peptide-2 enhances epithelial barrier function of both transcellular and paracellular pathways in the mouse (Abstract). Gastroenterol ogy 114: G4620, 1998.

2. Bertrand, V., R. Guimbaud, M. Tulliez, C. Mauprivez, P. Sogni, D. Couturier, J .-P. Giroud, S. Chaussade, and L. Chauvelot-Moachon. Increase in tumor necrosis factor- $\alpha$ production linked to the toxicity of indomethacin for the rat small intestine. Br. J . Pharmacol. 124: 1385-1394, 1998.

3. Bradley, P. P., D. A. Priebat, R. D. Christensen, and G. Rothstein. Measurement of cutaneous inflammation: estima- 
tion of neutrophil content with an enzyme marker. J. Invest. Dermatol. 78: 206-209, 1982.

4. Chance, W. T., T. Foley-Nelson, I. Thomas, and A. Balasubramaniam. Prevention of parenteral nutrition-induced gut hypoplasia by coinfusion of glucagon-like peptide-2. Am. J. Physiol. 273 (Gastrointest. Liver Physiol. 36): G559-G563, 1997.

5. Chomczynski, P., and N. Sacchi. Single-step method of RNA isolation by acid guanidinium thiocyanate-phenol-chloroform extraction. Anal. Biochem. 162: 156-159, 1987.

6. Drucker, D. J . The glucagon-like peptides. Diabetes 47: 159169, 1998

7. Drucker, D. J ., and P. L. Brubaker. Proglucagon gene expression is regulated by a cyclic AMP-dependent pathway in rat intestine. Proc. Natl. Acad. Sci. USA 86: 3953-3957, 1989.

8. Drucker, D. J ., L. DeForest, and P. L. Brubaker. Intestinal response to growth factors administered al one or in combination with human [Gly2]glucagon-like peptide 2. Am. J . Physiol. 273 (Gastrointest. Liver Physiol. 36): G1252-G1262, 1997.

9. Drucker, D. J., P. Ehrlich, S. L. Asa, and P. L. Brubaker. Induction of intestinal epithelial proliferation by glucagon-like peptide 2. Proc. Natl. Acad. Sci. USA 93: 7911- 7916, 1996.

10. Drucker, D. J., Q. Shi, A. Crivici, M. Sumner-Smith, W. Tavares, M. Hill, L. Deforest, S. Cooper, and P. L. Brubaker. Regulation of the biological activity of glucagon-like peptide 2 by dipeptidyl peptidase IV. NatureBiotechnol. 15: 673-677, 1997.

11. Drucker, D. J ., B. Yusta, R. P. Boushey, L. Deforest, and P. L. Brubaker. Human [Gly ${ }^{2}$ ]GLP-2 reduces the severity of colonic injury in a murine model of experimental colitis. Am. J . Physiol. 276 (Gastrointest. Liver Physiol. 39): G79-G91, 1999.

12. Edwards, C. M., J . F. Todd, M. Mahmoudi, Z. Wang, R. M. Wang, M. A. Ghatei, and S. R. B loom. Glucagon-like peptide 1 has a physiological role in the control of postprandial glucose in humans: studies with the antagonist exendin 9-39. Diabetes 48: 86- 93, 1999.

13. Egger, B., H. V. Carey, F. Procaccino, N.-N. Chai, E. P. Sandgren, J. Lakshmanan, V. S. Buslon, Q. W. French, M. W. Buchler, and V. E. Eysselein. Reduced susceptibility of mice overexpressing transforming growth factor $\alpha$ to dextran sodium sul phate colitis. Gut 43: 64- 70, 1998.

14. Egger, B., F. Procaccino, J . Lakshmanan, M. Reinshagen, P. Hoffman, A. Patel, W. Reuben, S. Gnanakkan, L. Liu, L. Barajas, and V. E. Eysselein. Mice lacking transforming growth factor $\alpha$ have an increased susceptibility to dextran sulfate-induced colitis. Gastroenterol ogy 113: 825-832, 1997.

15. Ettarh, R. R., and K. E. Carr. Structural and morphometric analysis of murine small intestine after indomethacin administration. Scand. J . Gastroenterol. 28: 795-802, 1993.

16. Housley, R. M., C. F. Morris, W. Boyle, B. Ring, R. Blitz, J . E. Tarpley, S. L. Aukerman, P. L. Devine, R. H. Whitehead, and G. F. Pierce. Keratinocyte growth factor induced proliferation of hepatocytes and epithelial cells throughout the rat gastrointestinal tract. J . Clin. Invest. 94: 1764-1777, 1994.

17. Kelly, D. A., C. Piasecki, A. Anthony, A. P. Dhillon, R. E. Pounder, and A.J . Wakefield. Focal reduction of villous blood flow in early indomethacin enteropathy: a dynamic vascular study in the rat. Gut 42: 366- 373, 1998.

18. Kolligs, F., H.-C. Fehmann, R. Göke, and B. Göke. Reduction of the incretin effect in rats by the glucagon-like peptide 1 receptor antagonist exendin (9-39) amide. Diabetes 44: 16-19, 1995.

19. Langenbach, R., S. G. Morham, H. F. Tiano, C. D. Loftin, B. I. Ghanayem, P. C. Chulada, J . F. Mahler, C. A. Lee, E. H. Goulding, K. D. Kluckman, H. S. Kim, and O. Smithies. Prostaglandin synthase 1 gene disruption in mice reduces arachidonic acid-induced inflammation and indomethacin-induced gastric ulceration. Cell 83: 483-492, 1995.

20. Leung, F. W., J. C. Miller, T. J. Reedy, and P. H. Guth. Exogenous prostaglandin protects against acid-induced deep mucosal injury by stimulating alkaline secretion in rat duodenum. Dig. Dis. Sci. 34: 1686- 1691, 1989.
21. Mashimo, H., D.-C. Wu, D. K. Podolsky, and M. C. Fishman. I mpaired defense of intestinal mucosa in mice lacking intestinal trefoil factor. Science 274: 262-265, 1996.

22. Mojsov, S., G. Heinrich, I. B. Wilson, M. Ravazzola, L. Orci, and J . F. Habener. Preproglucagon gene expression in pancreas and intestine diversifies at the level of post-translational processing. J . Biol. Chem. 261: 11880-11889, 1986.

23. Munroe, D. G., A. K. Gupta, P. Kooshesh, G. Rizkalla, H. Wang, L. Demchyshyn, Z.-J . Yang, R. K. Kamboj, H. Chen, K. McCallum, M. Sumner-Smith, D. J. Drucker, and A. Crivici. Prototypic G protein-coupled receptor for the intestinotrophic factor glucagon-like peptide 2. Proc. Natl. Acad. Sci. USA 96: 1569-1573, 1999.

24. Nygard, G., A. Anthony, C. Piasecki, M. A. Trevethick, M. Hudson, A. P. Dhillon, R. E. Pounder, and A. J . Wakefield. Acute indomethacin-induced jejunal injury in the rat: early morphological and biochemical changes. Gastroenterology 106: 567-575, 1994.

25. Playford, R. J ., T. Marchbank, N. Mandir, A. Higham, K. Meeran, M. A. Ghatei, S. R. Bloom, and R. A. Goodlad. Effects of keratinocyte growth factor (KGF) on gut growth and repair. J . Pathol. 184: 316-322, 1998.

26. Podolsky, D. K. Regulation of intestinal epithelial proliferation: a few answers, many questions. Am. J. Physiol. 264 (Gastrointest. Liver Physiol. 27): G179-G186, 1993.

27. Podolsky, D. K. Healing the epithelium: solving the problem from two sides. J . Gastroenterol ogy 32: 122-126, 1997.

28. Potten, C. S., and H. K. Grant. The relationship between ionizing radiation-induced apoptosis and stem cells in the small and large intestine. Br. J. Cancer 78: 993-1003, 1998.

29. Reuter, B. K., N. M. Davies, and J . L. Wallace. Non-steroidal antiinflammatory drug enteropathy in rats: role of permeability, bacteria, and enterohepatic circulation. Gastroenterology 112: 109- 117, 1997

30. Scott, R. B., D. Kirk, W. K. MacNaughton, and J . B. Meddings. GLP-2 augments the adaptive response to massive intestinal resection in rat. Am. J. Physiol. 275 (Gastrointest. Liver Physiol. 38): G911-G921, 1998.

31. Scrocchi, L. A., T. J . Brown, N. Maclusky, P. L. Brubaker, A. B. Auerbach, A. L. J oyner, and D. J . Drucker. Glucose intolerance but normal satiety in mice with a null mutation in the glucagon-like peptide receptor gene. Nature Med. 2: 12541258, 1996

32. Strober, W., B. R. L udviksson, and I.J . F uss. Thepathogenesis of mucosal inflammation in murine models of inflammatory bowel disease and Crohn disease. Ann. Int. Med. 128: 848- 856, 1998.

33. Targan, S. R., S. B. Hanauer, S. J . Van Deventer, L. Mayer, D. H. Present, T. Braakman, K. L. Dewoody, T. F. Schaible, and P. J . Rutgeerts. A short-term study of chimeric monoclonal antibody CA2 to tumor necrosis factor al pha for Crohn's disease. Crohn's Disease CA2 Study Group. N. Engl. J . Med. 337: 10291035, 1997

34. Tsai, C.-H., M. Hill, S. L. Asa, P. L. Brubaker, and D. J . Drucker. Intestinal growth-promoting properties of glucagonlike peptide 2 in mice. Am. J . Physiol. 273 (Endocrinol. Metab. 36): E 77-E 84, 1997

35. Wallace, J . L. N onsteroidal anti-inflammatory drugs and gastroenteropathy: the second hundred years. Gastroenterology 112: 1000-1016, 1997.

36. Wallace, J . L., K. E. Arfors, and G. W. McKnight. A monoclonal antibody against the CD18 leukocyte adhesion molecule prevents indomethacin-induced gastric damage in the rabbit. Gastroenterology 100: 878-883, 1991.

37. Wallace, J . L., C. M. Keenan, and D. N. Granger. Gastric ulceration induced by nonsteroidal anti-inflammatory drugs is a neutrophil-dependent process. Am. J . Physiol. 259 (Gastrointest. Liver Physiol. 22): G462-G467, 1990.

38. Wang, Z., R. M. Wang, A. A. Owji, D. M. Smith, M. A. Ghatei, and S. R. Bloom. Glucagon-like peptide 1 is a physiological incretin in rat. J . Clin. Invest. 95: 417-421, 1995.

39. Yamada, T., E. Deitch, R. D. Specian, M. A. Perry, R. B. Sartor, and M. B. Grisham. Mechanisms of acute and chronic intestinal inflammation induced by indomethacin. Inflammation 17: 641-662, 1993. 